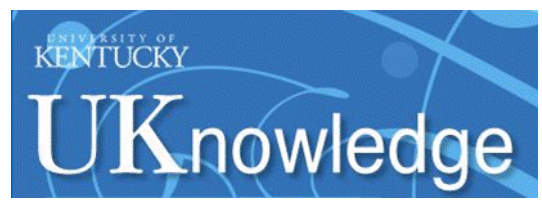

University of Kentucky

UKnowledge

\title{
Oxidation of Substituted Catechols at the Air-Water Interface: Production of Carboxylic Acids, Quinones, and Polyphenols
}

\author{
Elizabeth A. Pillar \\ University of Kentucky, epillar86@gmail.com \\ Marcelo I. Guzman \\ University of Kentucky, marcelo.guzman@uky.edu
}

Follow this and additional works at: https://uknowledge.uky.edu/chemistry_facpub

Part of the Agricultural Science Commons, Analytical Chemistry Commons, Atmospheric Sciences Commons, Biochemistry Commons, Environmental Chemistry Commons, Environmental Engineering Commons, Fresh Water Studies Commons, Laboratory and Basic Science Research Commons, Molecular and Cellular Neuroscience Commons, Organic Chemistry Commons, Physical Chemistry Commons, and the Wood Science and Pulp, Paper Technology Commons

Right click to open a feedback form in a new tab to let us know how this document benefits you.

\section{Repository Citation}

Pillar, Elizabeth A. and Guzman, Marcelo I., "Oxidation of Substituted Catechols at the Air-Water Interface: Production of Carboxylic Acids, Quinones, and Polyphenols" (2017). Chemistry Faculty Publications. 77. https://uknowledge.uky.edu/chemistry_facpub/77

This Article is brought to you for free and open access by the Chemistry at UKnowledge. It has been accepted for inclusion in Chemistry Faculty Publications by an authorized administrator of UKnowledge. For more information, please contact UKnowledge@lsv.uky.edu. 
Oxidation of Substituted Catechols at the Air-Water Interface: Production of Carboxylic Acids, Quinones, and Polyphenols

Digital Object Identifier (DOI)

https://doi.org/10.1021/acs.est.7b00232

Notes/Citation Information

Published in Environmental Science \& Technology, v. 51, no. 9, p. 4951-4959.

Copyright @ 2017 American Chemical Society

ACS AuthorChoice - This is an open access article published under an ACS AuthorChoice License, which permits copying and redistribution of the article or any adaptations for non-commercial purposes.

This article is available at UKnowledge: https://uknowledge.uky.edu/chemistry_facpub/77 


\title{
Oxidation of Substituted Catechols at the Air-Water Interface: Production of Carboxylic Acids, Quinones, and Polyphenols
}

\author{
Elizabeth A. Pillar and Marcelo I. Guzman*(i) \\ Department of Chemistry, University of Kentucky, Lexington, Kentucky 40506, United States \\ Supporting Information
}

ABSTRACT: Anthropogenic activities contribute benzene, toluene, and anisole to the environment, which in the atmosphere are converted into the respective phenols, cresols, and methoxyphenols by fast gas-phase reaction with hydroxyl radicals $\left(\mathrm{HO}^{\circ}\right)$. Further processing of the latter species by $\mathrm{HO}^{\bullet}$ decreases their vapor pressure as a second hydroxyl group is incorporated to accelerate their oxidative aging at interfaces and in aqueous particles. This work shows how catechol, pyrogallol, 3-methylcatechol, 4-methylcatechol, and 3-methoxycatechol (all proxies for oxygenated aromatics derived from benzene, toluene, and anisole) react at the air-water interface with increasing $\mathrm{O}_{3}(\mathrm{~g})$ during $\tau_{\mathrm{c}} \approx 1 \mu$ s contact time and contrasts their potential for electron transfer and in situ

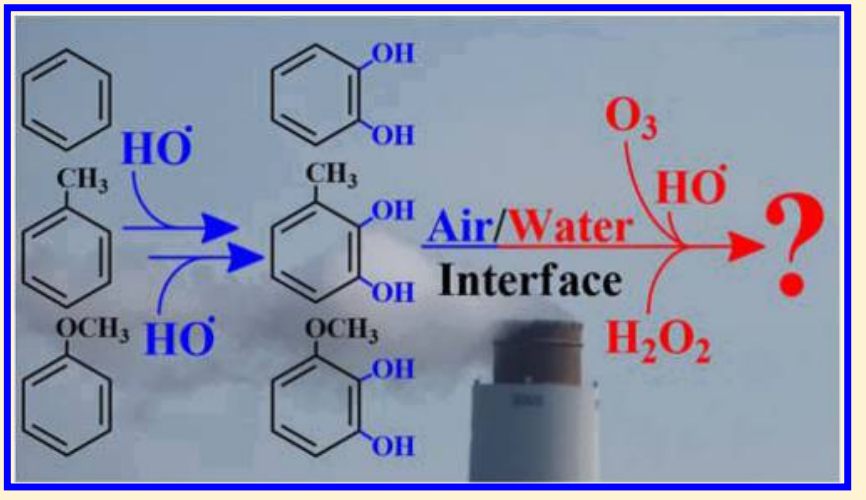
production of $\mathrm{HO}^{\bullet}$ using structure-activity relationships. A unifying mechanism is provided to explain the oxidation of the five proxies, which includes the generation of semiquinone radicals. Functionalization in the presence of $\mathrm{HO}^{\bullet}$ results in the formation of polyphenols and hydroxylated quinones. Instead, fragmentation produces polyfunctional low molecular weight carboxylic acids after oxidative cleavage of the aromatic bond with two vicinal hydroxy groups to yield substituted cis,cis-muconic acids. The generation of maleinaldehydic, maleic, pyruvic, glyoxylic, and oxalic acids confirms the potential of oxy aromatics to produce light-absorbing aqueous secondary organic aerosols in the troposphere.

\section{INTRODUCTION}

Chemical and physical processes resulting in the generation of secondary organic aerosol (SOA) particles that scatter and absorb sunlight and serve as ice and cloud condensation nuclei play an important role in the earth's radiation fluxes. ${ }^{1}$ Aromatic species emitted to the atmosphere during fossil fuel combustion and biomass burning (e.g., wildfires) processes provide phenol precursors for SOA formation through competing fragmentation and functionalization oxidation reactions. ${ }^{2,3}$ Previous work has explored the catalytic effect played by interfaces and the role of variable relative humidity $(\mathrm{RH})$ during the atmospheric oxidation of phenols, e.g., by $\mathrm{O}_{3}(\mathrm{~g})$ and hydroxyl radicals $\left(\mathrm{HO}^{\bullet}\right) .^{2-6} \mathrm{~A}$ combination of analytical methods (infrared spectroscopy, mass spectrometry (MS), and chromatography) employed in our laboratory revealed the importance of competitive oxidation mechanisms. ${ }^{2,3}$ The production of several reactive oxygen species (ROS), including the formation of semiquinone radicals, has been demonstrated, ${ }^{2,3}$ suggesting that aromatics provide a significant missing mechanism for the production of low-volatility species found in aerosols. ${ }^{2,3}$ Furthermore, the common products identified during offline analysis of reactions lasting a few hours and in situ studies under a few microseconds of contact time $\left(\tau_{\mathrm{c}}\right)$ validated a flowthrough ultrafast interfacial oxidation MS setup for inspecting reactions at the air-water interface. ${ }^{2,3}$
Combustion and biomass burning emissions provide the two main aromatic species to the atmosphere, benzene and toluene, that total 5.6 and $6.9 \mathrm{Tg}$ of $\mathrm{C} \mathrm{y}^{-1}$, respectively. ${ }^{7}$ We have previously explained that the oxidative processing of benzene by hydroxyl radicals $\left(\mathrm{HO}^{\bullet}\right)$ consecutively yields phenol (reaction R1, Scheme 1) and dihydroxybenzenes such as catechol (reaction R2) with gas-phase rate constants $k_{\mathrm{R} 1 \text {; benzene+HO}}=1.2 \times 10^{-12} \mathrm{~cm}^{3}$ molecule $^{-1} \mathrm{~s}^{-18}$ and $k_{\mathrm{R} 2 \text {; phenol }+\mathrm{HO}} \cdot=2.7 \times 10^{-11} \mathrm{~cm}^{3}$ molecule ${ }^{-1} \mathrm{~s}^{-1}$, , respectively. ${ }^{2,3}$ The aromatic structures and names, the ring functionalization reactions (e.g., numbered as reactions $\mathrm{R} 1, \mathrm{R} 2$, etc.), and the products formed and their $\mathrm{m} / z$ values are introduced in Scheme 1 and Tables S1 and S2 (Supporting Information). By analogy to the reactivity observed for benzene, reactions $\mathrm{R} 1$ and $\mathrm{R} 2$ also show that toluene $\left(k_{\mathrm{R} 1 \text {; toluene+HO}}=5.6 \times 10^{-12} \mathrm{~cm}^{3}\right.$ molecule $\left.\mathrm{e}^{-1} \mathrm{~s}^{-1}\right)^{8}$ can generate methylphenols $(p-, m$-, and $o$ cresols) and dihydroxytoluenes (e.g., $k_{\mathrm{R} 2 ; 2 \text {-methylphenol+HO}}{ }^{\circ}=4.3 \times$ $10^{-11} \mathrm{~cm}^{3}$ molecule $\left.{ }^{-1} \mathrm{~s}^{-1}\right)^{10}$ such as 3- or 4-methylcatechol, respectively. In addition, by consecutive hydrogen abstractions from the $-\mathrm{CH}_{3}$ group of toluene, reactions $\mathrm{R} 3 \mathrm{a}$ and $\mathrm{R} 3 \mathrm{~b}$ show

Received: January 12, 2017

Revised: March 26, 2017

Accepted: April 10, 2017

Published: April 10, 2017 
Scheme 1. Proposed Sequential Oxidation Mechanisms of (Black Bold Font) Benzene, (Blue Bold Font) Toluene, and (Red Bold Font) Anisole in the (Purple Font and Reactions) Gas Phase by Hydroxyl Radicals, Which Continue at the (Green Font and Reactions) Air-Water Interface and in Aqueous Particles after Partitioning of the Corresponding Substituted Catechols ${ }^{a}$

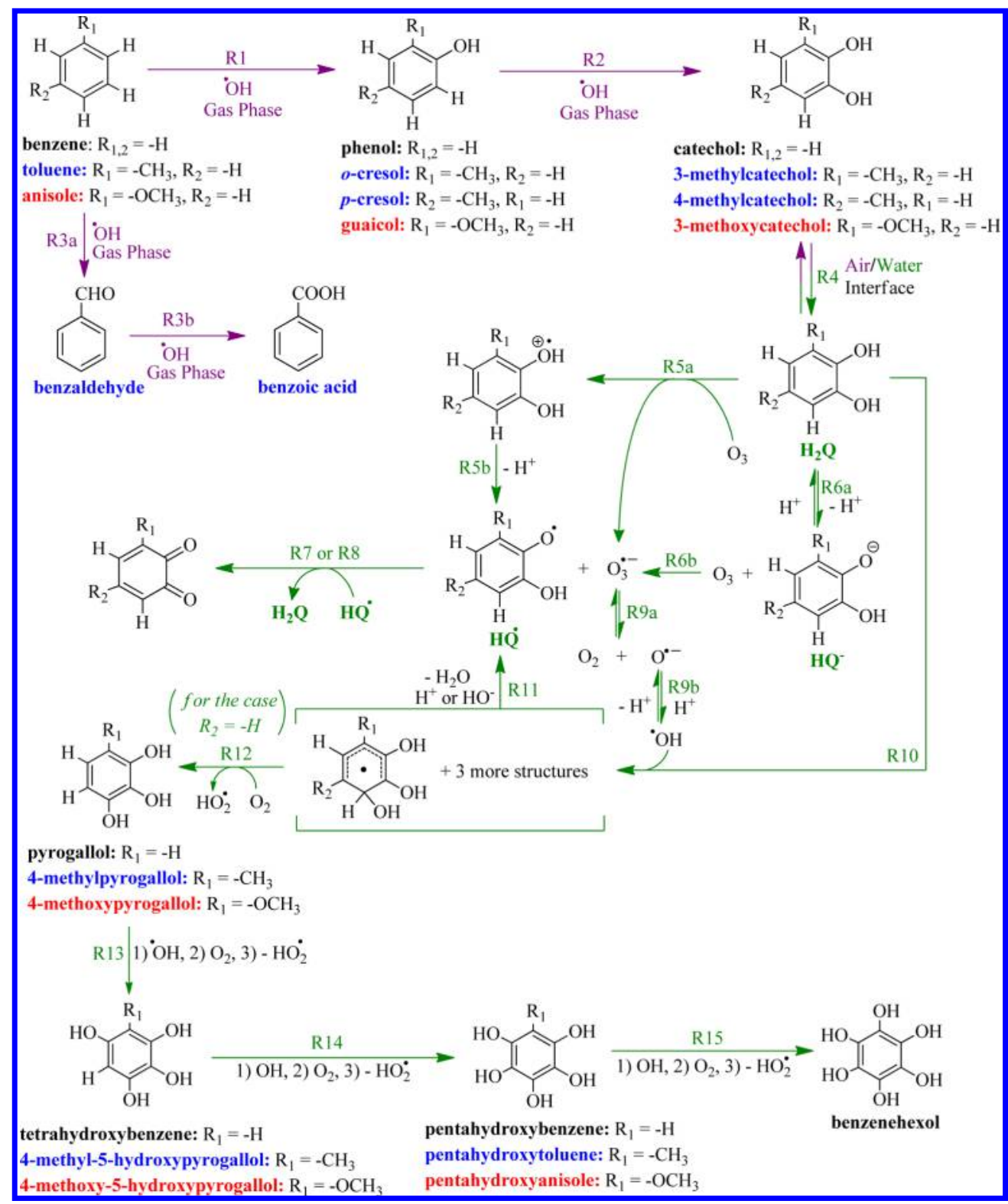

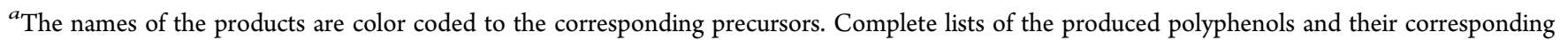
quinone redox pairs are available in Tables S1 and S2 (Supporting Information) with the observed $\mathrm{m} / \mathrm{z}$ values.

that benzaldehyde and benzoic acid can be produced. In general, phenols and dihydroxybenzenes ${ }^{11}$ with methoxy $\left(-\mathrm{OCH}_{3}\right)$, methyl $\left(-\mathrm{CH}_{3}\right)$, carbonyl $(\mathrm{C}=\mathrm{O})$, and carboxylic acid $(-\mathrm{COOH})$ substituent groups $(-\mathrm{R})$ are ubiquitous aromatic species in the atmosphere, as proved from the analysis of cloudwater that has scavenged combustion and biomass burning emissions. ${ }^{12}$ The surfactant properties ${ }^{13,14}$ of these polyfunctional phenols make them especially susceptible to undergo oxidations as they accumulate at the air-water interface or partition into aqueous particles (reaction R4). ${ }^{2,3}$

In this work, the interfacial oxidations of a series of substituted catechols found in the environment are contrasted to understand their reactivity and potential for electron transfer during ultrafast contact $\left(\tau_{\mathrm{c}} \approx 1 \mu \mathrm{s}\right)$ and detection $\left(\tau_{\mathrm{d}} \approx 1 \mathrm{~ms}\right)$ times. ${ }^{2,15,16}$ Electron-density-donating substituents of the aromatic ring alter the reactivity of each molecule relative to catechol. Mass spectral data confirm the interfacial production of short-lived species can proceed through two pathways: (1) functionalization of the aromatic ring by hydroxylation and (2) fragmentation of the aromatic ring and intermediates by ozone $\left(\mathrm{O}_{3}(\mathrm{~g})\right)$-driven oxidative cleavage. ${ }^{2,3}$ The first pathway implies that semiquinone radicals are formed en route to more hydroxylated aromatic and quinone products. In the alternate pathway, the fragmentation of unsaturated $\mathrm{C}=\mathrm{C}$ bonds provides polyfunctional low molecular weight carboxylic acids $^{2,3}$ widely found in tropospheric aerosols. ${ }^{1}$

\section{EXPERIMENTAL SECTION}

Sample Preparation. Solutions of catechol (Sigma-Aldrich, 99.9\%), pyrogallol (Acros, 99.7\%), 3-methylcatechol (TCI, 
99.8\%), 3-methoxycatechol (Aldrich, 99.7\%), and 4-methylcatechol (Acros, 97.6\%) were freshly prepared in degassed ultrapure water $(18.2 \mathrm{M} \Omega \mathrm{cm}$, Elga Purelab flex, Veolia) and infused into a calibrated ESI-MS instrument (Thermo Scientific, MSQ Plus) operating in the negative ionization mode. Stock solutions of ca. $5.00 \mathrm{mM}$ were diluted to $100.0 \mu \mathrm{M}$ final concentration after adjustment of the $\mathrm{pH}$ with $0.01 \mathrm{M}$ $\mathrm{NaOH}$ (Fisher, 99.3\%) as measured with a calibrated $\mathrm{pH}$ meter (Mettler Toledo). The figures report the percent normalized anion count $\left(I_{m / z}\right)$ at specific mass-to-charge $(\mathrm{m} / z)$ ratios for experiments at $\mathrm{pH} 7.80$. While the oxidations were explored in the atmospheric relevant $\mathrm{pH}$ range 5-10, reporting the results at $\mathrm{pH} 7.8$ provides an example case that demonstrates the complexity of all the chemistry observed. Anthropogenic biomass burning emissions from agricultural practices often coincide with increased ammonia $\left(\mathrm{NH}_{3}\right)$ emissions from livestock and fertilizers, ${ }^{18,19}$ which explains why fine particulate matter around agricultural regions can be predominately alkaline. ${ }^{20-23}$ For example, in most of the Midwest Region and the Pacific Coast of the United States, where agriculture is a primary economic activity, $\mathrm{NH}_{3}$ emissions are estimated to be sufficient to neutralize all acidic components. ${ }^{21}$ Thus, even fine aerosols can be neutral or slightly basic, which indicates the experiments reported are of atmospheric relevance. All experiments are performed in duplicate.

Oxidation of Substituted Catechols. The ESI-MS flowthrough reactor to investigate ultrafast oxidations at the airwater interface has been described in depth. ${ }^{15,16}$ The $100 \mu \mathrm{M}$ aqueous solution of the selected substituted catechol undergoes pneumatically assisted aerosolization to form a fine mist of micrometer size droplets at ambient pressure. A spark discharge

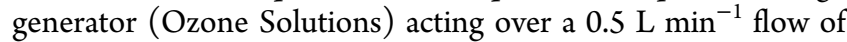
$\mathrm{O}_{2}(\mathrm{~g})$ (Scott-Gross, UHP) produces $\mathrm{O}_{3}(\mathrm{~g})$, which is quantified in a $10 \mathrm{~cm}$ path length cuvette (Starna cell) by UV absorption spectrophotometry (Evolution Array UV-visible spectrophotometer, Thermo Scientific) after dilution with $0.0-5.0 \mathrm{~L} \mathrm{~min}^{-1}$ of $\mathrm{N}_{2}(\mathrm{~g})$ (Scott Gross, UHP) in a flow-through borosilicate chamber $\left(3.785 \mathrm{~L}\right.$ capacity). ${ }^{24}$ In the final stage, $\mathrm{O}_{3}(\mathrm{~g})$ is diluted 61-fold with the $\mathrm{N}_{2}(\mathrm{~g})$ nebulizing gas $\left(12.0 \mathrm{~L} \mathrm{~min}{ }^{-1}\right)$. The interface of the microdroplets containing substituted catechols encounters a $0.2 \mathrm{~L} \mathrm{~min}^{-1}$ flow of $0 \mathrm{ppbv} \leq\left[\mathrm{O}_{3}(\mathrm{~g})\right] \leq$ 3 ppmv during a few microseconds. ${ }^{15,16}$ If oxidized species are produced, they are observed as anions by the mass spectrometer at specific $\mathrm{m} / \mathrm{z}$ values (reported in the text, figures, and schemes) in less than $1 \mathrm{~ms}$ after their formation. ${ }^{15,16}$ The experimental conditions employed were the same used during the previous study with catechol and trihydroxybenzenes: ${ }^{2}$ nebulizer pressure, $70 \mathrm{psi}$; nebulizer voltage, $-1.9 \mathrm{kV}$; cone voltage, $-50 \mathrm{~V}$; drying gas temperature, $250{ }^{\circ} \mathrm{C}$. Reported $I_{m / z}$ values correspond to solvent background subtracted raw data acquired at fixed time intervals (e.g., time $\geq 30 \mathrm{~s}$ ).

The conversion of terephthalic acid (Acros, 99.0\%) to 2hydroxyterephthalic acid (TCI, 98.3\%) with a rate constant $k_{\text {terephthalic acid }+\mathrm{HO}}{ }^{\circ}=4 \times 10^{9} \mathrm{M}^{-1} \mathrm{~s}^{-1}$ was used for in situ quantification of $\mathrm{HO}^{\bullet}$ at the air-water interface. ${ }^{25}$ The reaction of $100 \mu \mathrm{M}$ (1) pyrogallol, (2) 4-methylcatechol, (3) 3methylcatechol, and (4) 3-methoxycatechol with $2.7 \mathrm{ppmv}$ $\mathrm{O}_{3}(\mathrm{~g})$ was studied at $\mathrm{pH} 7.8$ in the presence of $5 \mu \mathrm{M}$ terephthalic acid. The characteristic product peak at $\mathrm{m} / z 181$ for 2-hydroxyterephthalic acid was used to quantify the production of $\mathrm{HO}^{\bullet}$ by standard addition after subtraction of the background produced during the controls under 1 atm of $\mathrm{N}_{2}(\mathrm{~g})$.

\section{RESULTS AND DISCUSSION}

Reactions of Substituted Catechols at the Air-Water Interface. The interfacial oxidation of $100 \mu \mathrm{M}$ substituted catechols was examined in the absence of $\mathrm{O}_{3}(\mathrm{~g})$ or in its presence for mixing ratios of $0.223,0.989,1.760$, and 2.420 ppm. For example, Figure 1 shows ESI mass spectra of

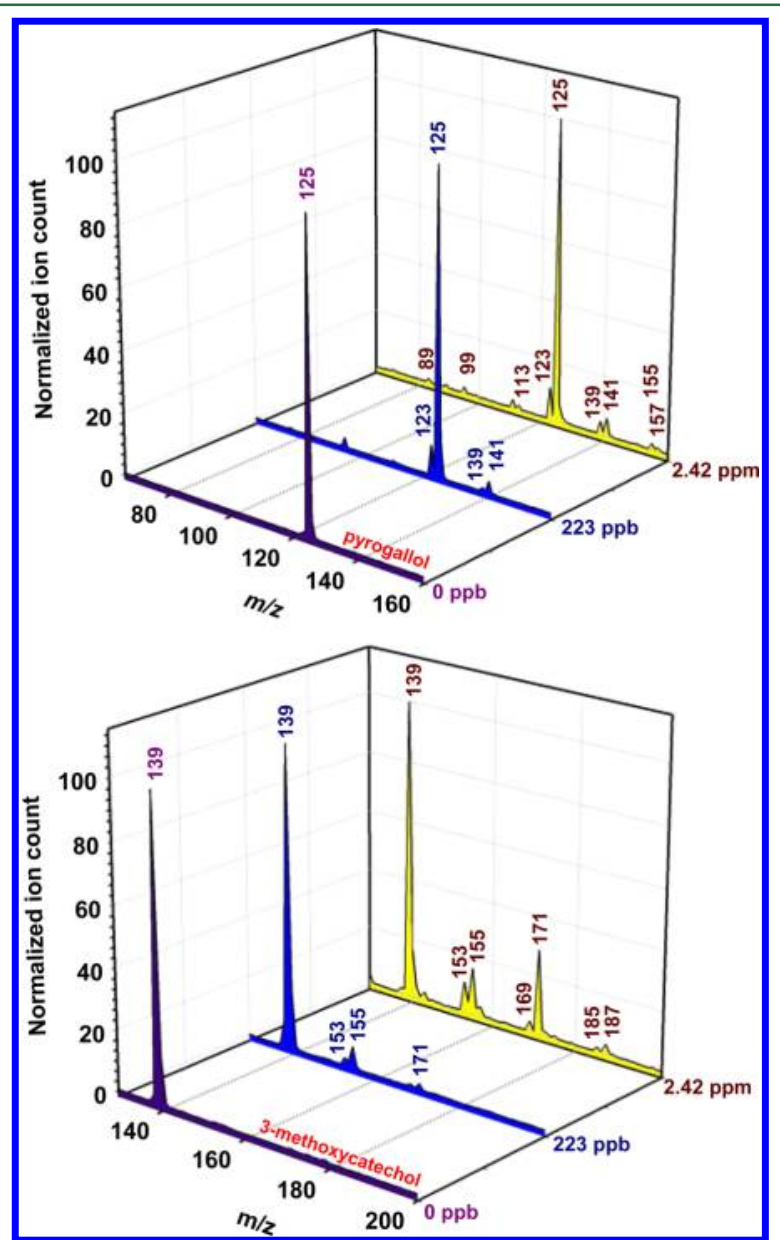

Figure 1. ESI-MS spectra of $100 \mu \mathrm{M}$ solutions of (top) pyrogallol and (bottom) 3-methoxycatechol at $\mathrm{pH} 7.8$ exposed to a $0.200 \mathrm{~L} \mathrm{~min}^{-1}$ flow of (purple trace) $1 \mathrm{~atm}$ of $\mathrm{N}_{2}(\mathrm{~g})$, (blue trace) $223 \mathrm{ppb} \mathrm{O}_{3}(\mathrm{~g})$, and (yellow trace) $2.42 \mathrm{ppm} \mathrm{O}_{3}(\mathrm{~g})$. Ion count values are normalized percentages relative to the most intense peak in each mass spectrum, $I_{125}$ for pyrogallol and $I_{139}$ for 3-methoxycatechol.

aerosolized aqueous solutions of (top) pyrogallol and (bottom) 3-methoxycatechol at $\mathrm{pH} 7.8$ impinged by a flow of $0.2 \mathrm{~L} \mathrm{~min}^{-1}$ of $0 \mathrm{ppb}, 223 \mathrm{ppb}$, and $2.42 \mathrm{ppm}_{3}(\mathrm{~g})$. Both traces in the absence of $\mathrm{O}_{3}(\mathrm{~g})$ display the anions of pyrogallol $(\mathrm{m} / z 125)$ and methoxycatechol $(m / z 139)$. For comparison, experiments with catechol $\left(m / z\right.$ 109) have been studied in detail. ${ }^{2}$ The direct oxidation of catechol by $\mathrm{O}_{3}(\mathrm{~g})$ has been shown to produce glyoxylic acid $(m / z 73)$, oxalic acid $(m / z 89)$, maleinaldehydic acid $(\mathrm{m} / z$ 99), 5-oxo-3-pentenoic acid $(\mathrm{m} / z$ 113), maleic acid $(m / z 115)$, 3-hydroxy-o-quinone or 4hydroxy-o-quinone $(m / z 123), 1,2,3-$ and 1,2,4-tryhydroxybenzenes $(m / z 125)$, glutaconic acid $(m / z 129)$, 3,4-dihydroxy-oquinone or 3,6-dihydroxy-o-quinone $(\mathrm{m} / z \mathrm{139})$, cis,cis-muconic acid, 1,2,3,4- and 1,2,4,5-tetrahydroxybenzenes $(m / z$ 141), 
3,4,5-tridihydroxy-o-quinone and 3,4,6-tridihydroxy-o-quinone $(m / z 155)$, pentahydroxybenzene $(m / z 157)$, and benzenehexol $(m / z 173) .^{2}$

Following the oxidation channels exhibited by catechol, it is possible to assign the products for pyrogallol in Figure 1 to also be oxalic acid $(\mathrm{m} / z$ 89), maleinaldehydic acid $(\mathrm{m} / z$ 99), 5-oxo3-pentenoic acid $(\mathrm{m} / \mathrm{z} 113), 3$ - and 4-hydroxy-o-quinones $(\mathrm{m} / \mathrm{z}$ 123), 3,4-dihydroxy-o-quinone $(m / z 139)$, 1,2,3,4-tryhydroxybenzene and 2-hydroxy-cis,cis-muconic acid (both $\mathrm{m} / \mathrm{z} 141$ ), 3,4,5-tridihydroxy-o-quinone $(\mathrm{m} / z \mathrm{155})$, and pentahydroxybenzene $(m / z 157)$. Similarly, Figure 1 shows that 3methoxycatechol $(m / z 139)$ is oxidized to give the hydroxylated products 4-methoxypyrogallol or 3-methoxy-4-hydroxycatechol $(m / z 155)$ and their corresponding quinone pairs, e.g., 3-methoxy-6-hydroxy-o-quinone and 3-methoxy-4-hydroxy-o-quinone $(\mathrm{m} / \mathrm{z}$ 153), 4-methoxy-5-hydroxypyrogallol or 3-methoxy-4,5-dihydroxycatechol $(\mathrm{m} / z \quad 171)$ and their corresponding quinones pairs, e.g., 3-methoxy-4,6-dihydroxy$o$-quinone and 3-methoxy-4,5-dihydroxy-o-quinone $(\mathrm{m} / z 169)$, and 4-methoxy-5,6-dihydroxy-pyrogallol $(\mathrm{m} / z$ 187) and its corresponding 3-methoxy-4,5,6-trihydroxy-o-quinone $(\mathrm{m} / \mathrm{z}$ $185)$. When comparing the pairs at $\mathrm{m} / z 155$ and $153, \mathrm{~m} / z$ 171 and 169 , and $m / z \quad 187$ and 185 , for oxidized 3methoxycatechol (Figure 1), it is obvious that the peak for the dihydroxylated product of 3-methoxycatechol at $\mathrm{m} / z 171$ largely exceeds the expected value from correlation to the peak at $\mathrm{m} / \mathrm{z} 169$. For these quinone/hydroquinone pairs (signals separated by $2 \mathrm{amu}$ ), it is obvious that the peak at $\mathrm{m} / z 171$ displays a large contribution of another species, which is 2methoxymuconic acid, the major product from aromatic ring cleavage.

Figure 2 displays the ESI mass spectra for aerosolized solutions of (top) 3-methylcatechol and (bottom) 4-methylcatechol under the same conditions listed for Figure 1. Both traces in the absence of $\mathrm{O}_{3}(\mathrm{~g})$ display the anion for methylcatechol $(m / z 123)$ and a small peak for its dihydrate $(m / z 159)$, a feature also exhibited by catechol. Some of the products observed during the oxidation of both methylcatechols are oxalic acid $(m / z 89)$, maleinaldehydic acid $(m / z 99)$, 4-methyl-o-quinone $(\mathrm{m} / z$ 121) (no 3-methyl-o-quinone is registered probably due to steric impediments), 3-methyl-4hydroxy-, 3-hydroxy-4-methyl-, and 4-methyl-5-hydroxy-oquinones $(\mathrm{m} / z$ 137), 3-methyl-4-hydroxycatechol, 4-methylpyrogallol, and 4-methyl-5-hydroxycatechol $(\mathrm{m} / z$ 139), 3methyl-4,5-dihydroxy- and 3,5-dihydroxy-4-methyl-o-quinones $(\mathrm{m} / z$ 153), 2-methyl-cis,cis-muconic acid $(\mathrm{m} / z$ 155), 3-methyl4,5-dihydroxy- and 3,5-dihydroxy-4-methyl-catechols $(\mathrm{m} / z$ 155), 4-methyl-3,5,6-trihydroxy-o-quinone $(\mathrm{m} / z \mathrm{171})$, and 3methyl-4,5,6-trihydroxy- and 3,5,6-trihydroxy-4-methyl-catechols $(m / z 173)$.

Figure 3 gathers information from experiments with increasing $\left[\mathrm{O}_{3}(\mathrm{~g})\right]$ displaying the exponential drop of $I_{m / z}$ for pyrogallol, 3-methylcatechol, 4-methylcatechol, and 3-methoxycatechol. In agreement with our previous work with catechol, ${ }^{2}$ the information in Figure 3 suggests the first-order reaction on $\left[\mathrm{O}_{3}\right]$ for all the substituted catechols studied takes place within $\tau_{\mathrm{c}} \approx 1 \mu \mathrm{s}$. Indeed, the reaction with $\mathrm{O}_{3}(\mathrm{~g})$ molecules occurs at the outermost layers of the interface of a few nanometers thickness without diffusion limitations while replenishment of the organic molecule from the core is facilitated. ${ }^{2,16}$

Electron and Proton Transfers. The speciation of the substituted catechols in Figures 1 and 2 can be calculated using

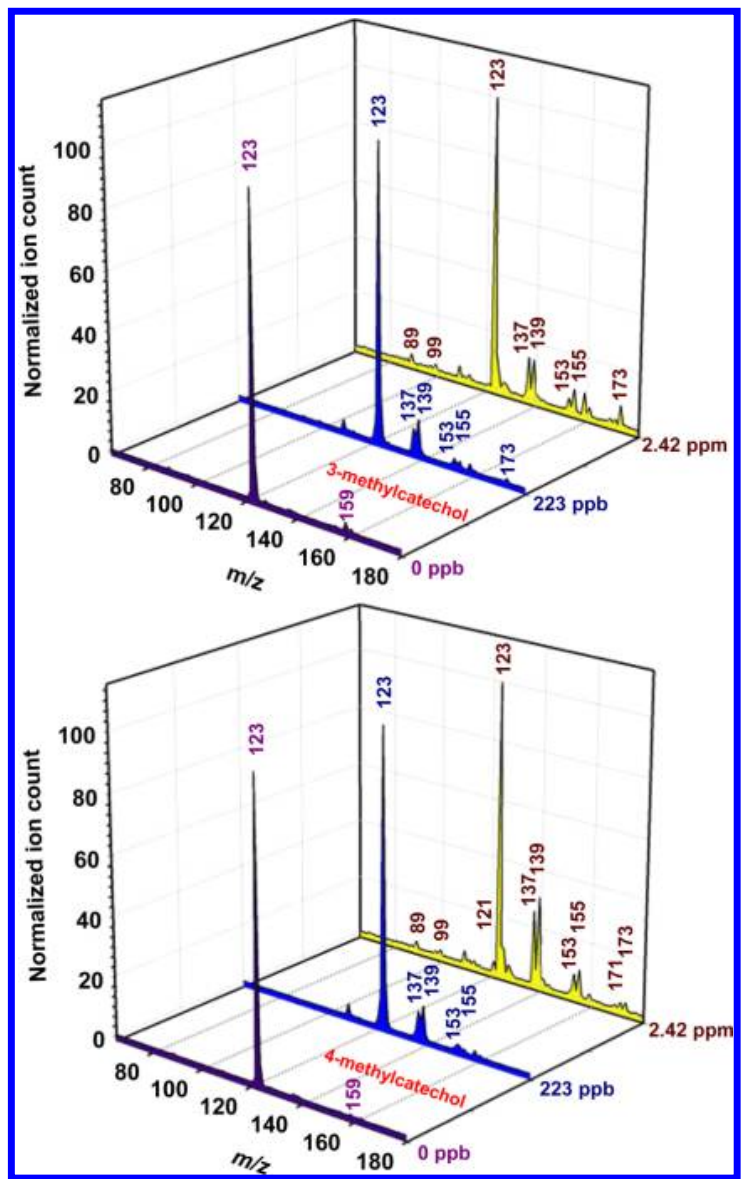

Figure 2. ESI-MS spectra of $100 \mu \mathrm{M}$ solutions of (top) 3methylcatechol and (bottom) 4-methylcatechol at $\mathrm{pH} 7.8$ exposed to a $0.200 \mathrm{~L} \mathrm{~min}^{-1}$ flow of (purple trace) $1 \mathrm{~atm}$ of $\mathrm{N}_{2}(\mathrm{~g})$, (blue trace) $223 \mathrm{ppb} \mathrm{O}_{3}(\mathrm{~g})$, and (yellow trace) $2.42 \mathrm{ppm} \mathrm{O}_{3}(\mathrm{~g})$. Ion count values are normalized percentages relative to $I_{123}$, the most intense peak in each mass spectrum.

both $\mathrm{p} K_{\mathrm{a} 1}$ and $\mathrm{p} K_{\mathrm{a} 2}$ for these weak diprotic species $\left(\mathrm{H}_{2} \mathrm{Q}\right)$ and their intermediate form $\left(\mathrm{HQ}^{-}\right)$:

$$
\begin{aligned}
& \mathrm{H}_{2} \mathrm{Q} \rightleftarrows \mathrm{HQ}^{-}+\mathrm{H}^{+} \quad \mathrm{pK}_{\mathrm{a} 1} \\
& \mathrm{HQ}^{-} \rightleftarrows \mathrm{HQ}^{2-}+\mathrm{H}^{+} \quad \mathrm{pK}_{\mathrm{a} 2}
\end{aligned}
$$

While this information is available for catechol and pyrogallol, ${ }^{22}$ the instability of this class of compounds precludes access to experimental values of the other acid dissociation constants. However, theoretical methods capable of accurately predicting $\mathrm{p} K_{\mathrm{a} 1}$ and $\mathrm{p} K_{\mathrm{a} 2}$ values have been developed. ${ }^{26-28}$ Thus, Table 1 combines the experimental and theoretical values for $\mathrm{p} K_{\mathrm{a} 1}$ and $\mathrm{p} K_{\mathrm{a} 2}$, which can be used to solve the speciation of the $\mathrm{H}_{2} \mathrm{Q}$ species vs $\mathrm{pH}$. For example, at working $\mathrm{pH} 7.8$, the fractions of fully associated catechols, $\alpha_{\mathrm{H}_{2} \mathrm{Q}} \geq 0.95$, and their intermediate monoprotic acid, $\alpha_{\mathrm{HQ}^{-}} \leq 0.05$, are reported in Table 1. Clearly, the diprotic catechols are the dominant species available for the oxidations displayed in Figures 1 and 2.

Under the oxidizing experimental conditions, the substituted catechols and/or their products can act as two-electron reductants, getting converted into the corresponding quinones by two coexisting pathways. The first pathway proceeds through initial electron transfer from the more abundant undissociated catechols to $\mathrm{O}_{3}$ (reaction $\mathrm{R} 5 \mathrm{a}$ ). This electron transfer pathway is supported by the dominant fractions in 


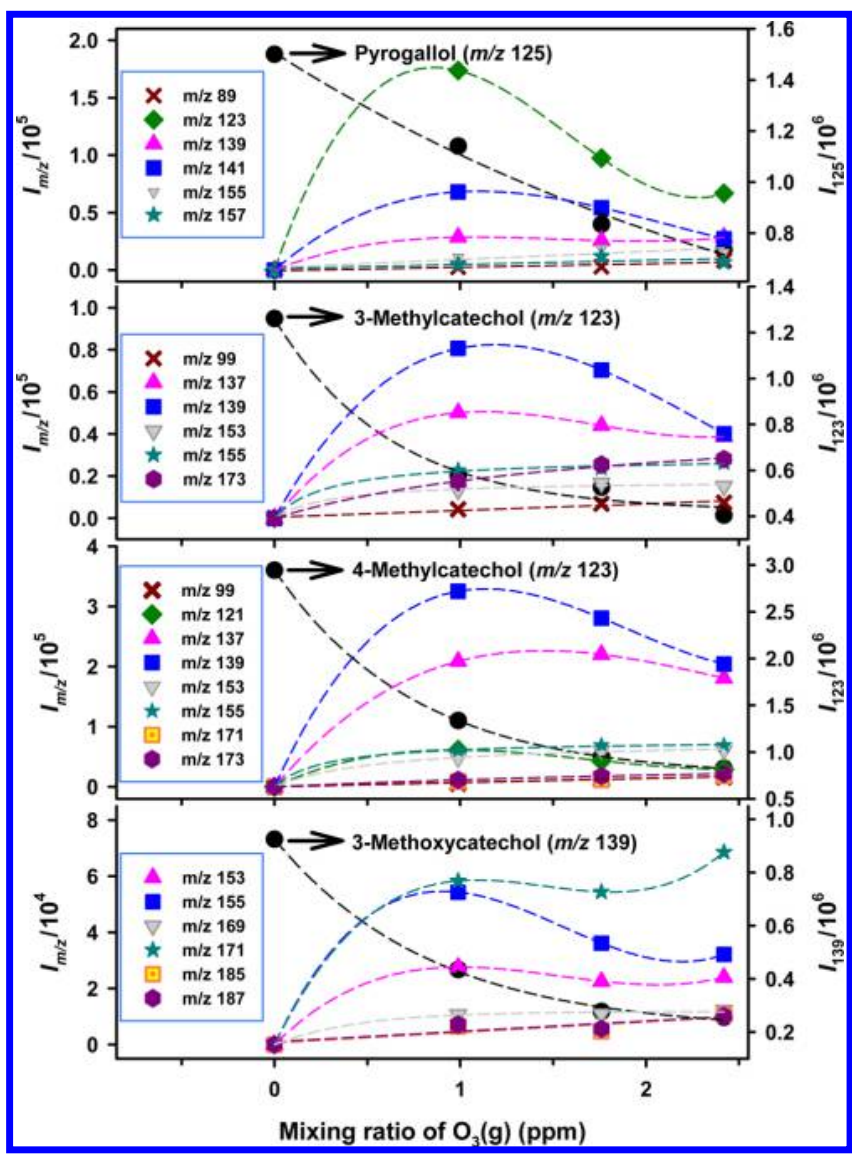

Figure 3. Ion count, $I_{m / z}$, of pyrogallol $(m / z 125)$, 3-methylcatechol $(\mathrm{m} / \mathrm{z}$ 123), 4-methylcatechol $(\mathrm{m} / z$ 123), 3-methoxycatechol $(\mathrm{m} / \mathrm{z}$ 139 ), and the respective oxidation products from exposing aerosolized solutions of each compound to increasing mixing ratios of $\mathrm{O}_{3}(\mathrm{~g})$.

equilibrium at $\mathrm{pH} 7.8, \alpha_{\mathrm{H}_{2} \mathrm{Q}} \geq 0.95$ (Table 1), which continues by a fast proton transfer (reaction R5b). Reactions R5a and $\mathrm{R} 5 \mathrm{~b}$ are equivalent to the net loss of a hydrogen atom. However, direct hydrogen atom transfer should be unfavorable in these molecular ensembles as exemplified by the $\sim 10$-fold larger hydrogen bond dissociation energies, calculated from data in dimethyl sulfoxide, ${ }^{29}$ than the thermal energy available for the system. The second mechanism involves initial dissociation of the diprotic catechols followed by electron transfer (reactions R6a and R6b), which is less likely to be the dominant process given $\alpha_{\mathrm{HQ}^{-}} \leq 0.05$ (Table 1). The equilibrium constant for reaction R6a corresponds to the first acid dissociation constant, $K_{\mathrm{a} 1}$. The self-reaction of two semiquinone radicals $\left(\mathrm{HQ}^{\bullet}\right)$ via reaction $\mathrm{R} 7$ finally produces a quinone $(\mathrm{Q})$ while regenerating a substituted catechol: $2 \mathrm{HQ}^{\bullet}$ $\rightarrow \mathrm{Q}+\mathrm{H}_{2} \mathrm{Q}$. Analogously, the cross-reaction between two different semiquinone radicals also generates a quinone: $\mathrm{HQ}_{i}{ }^{\bullet}+$ $\mathrm{HQ}_{i}^{\bullet} \rightarrow \mathrm{Q}_{i}+\mathrm{H}_{2} \mathrm{Q}_{i}$ (reaction R8).

The electron-donating capacity of the substituents and their position relative to the $-\mathrm{OH}$ groups should be considered together with molecular specific properties (e.g., redox potentials and first and second proton dissociation constants) to understand why reactions $\mathrm{R} 5$ and $\mathrm{R} 5 \mathrm{~b}$ are favored herein. Table 1 also lists the one-electron redox potentials of the semiquione radical cation $\left(\mathrm{HQ}^{\bullet+}\right)$ and undissociated substituted catechol pairs, $E_{\mathrm{HQ}^{\circ+} / \mathrm{H}_{2} \mathrm{Q}}$, which except for catechol reported at $\mathrm{pH} 7^{30}$ are predicted using structure-activity relationships derived from computational methods. ${ }^{29}$ The linear dependence of the redox potentials vs the normal hydrogen electrode (NHE) on the sum of the Hammett substituent parameters $(\sigma)$ available in the literature is given by the following equation: ${ }^{29}$

$$
E_{\mathrm{HQ}^{\bullet+} / \mathrm{H}_{2} \mathrm{Q}}=1.85 \sum_{i} \sigma_{i}+0.46
$$

Table 1 reports the positive $\Delta E=E_{\mathrm{O}_{3} / \mathrm{O}_{3}}{ }^{--}-E_{\mathrm{H}_{2} \mathrm{Q}^{*+} / \mathrm{H}_{2} \mathrm{Q}}$ for electron transfer (reaction $\mathrm{R} 5 \mathrm{a}$ ) between the substituted

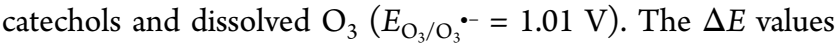
correspond to thermodynamically favorable processes as indicated in Table 1 by the calculated $\Delta G^{\circ}=-n F \Delta E$, where $n=1$ and $F=96.485 \mathrm{~kJ} \mathrm{~mol}^{-1} \mathrm{~V}^{-1}$ is the Faraday constant. From the increasing $\Delta E$ values in Table 1 , it is observed that electron transfer occurs more easily following the trend catechol $<$ pyrogallol $<4$-methylcatechol = 3-methylcatechol $<3$-methoxycatechol. In other words, the decreasing $E_{\mathrm{H}_{2} \mathrm{Q}^{*} / \mathrm{H}_{2} \mathrm{Q}}$ observed with these electron-donating groups favors electron transfer from $\mathrm{H}_{2} \mathrm{Q}$ to $\mathrm{O}_{3}$ (reaction $\mathrm{R} 5 \mathrm{a}$ ). The directly generated semiquinone radicals $\mathrm{H}_{2} \mathrm{Q}^{\bullet+}\left(\mathrm{p} K_{\mathrm{a} 1} \approx-1\right)^{31}$ promptly release a proton (reaction $\mathrm{R} 5 \mathrm{~b}$ ), while the ozonide radical anion $\mathrm{O}_{3}{ }^{\bullet-}$ from reaction $\mathrm{R} 5$ a coexists in equilibrium $\mathrm{R} 9 \mathrm{a}$ with very basic $\mathrm{O}^{\bullet-}\left(\mathrm{p} K_{\mathrm{a}}=11.8\right) .^{32}$ Therefore, for environmentally relevant atmospheric waters and other aqueous systems $(\mathrm{pH}<10)$ and in the present experiments, $\mathrm{O}^{\bullet-}$ is quickly converted into $\mathrm{HO}^{\bullet}$ (equilibrium $\mathrm{R} 9 \mathrm{~b}$ ). As a consequence, this work also provides an opportunity to understand how $\mathrm{HO}^{\bullet}$ continues the oxidation of substituted catechols at the air-water interface, in aqueous aerosols, and in other relevant water media.

Reactions of the Substituted Catechols with $\mathrm{HO}^{\circ}$. In addition to reactions $\mathrm{R} 7$ and $\mathrm{R} 8$, the semiquinone radicals can also be produced by the attack of $\mathrm{HO}^{\bullet}$ on the catechols (reaction R10), which generates resonance-stabilized cyclohexadienyl radicals capable of undergoing fast acid- or basecatalyzed elimination of water (reaction R11). For instance, reaction $\mathrm{R} 10$ for unsubstituted catechol proceeds at $\mathrm{pH} 9$ with

\section{Table 1}

\begin{tabular}{lccccccccc}
\multicolumn{1}{c}{ name } & $\mathrm{MW}(\mathrm{amu})$ & $\mathrm{p} K_{\mathrm{a} 1}$ & $\mathrm{p} K_{\mathrm{a} 2}$ & $\alpha_{\mathrm{H}_{2} \mathrm{Q}}{ }^{d}$ & $\alpha_{\mathrm{HQ}^{-}}{ }^{d}$ & $E_{\mathrm{H}_{2} \mathrm{C}^{+} / \mathrm{H}_{2} \mathrm{C}^{e}}(\mathrm{~V})$ & $\Delta E^{h}(\mathrm{~V})$ & $\Delta G^{\circ i}\left(\mathrm{~kJ} \mathrm{~mol}{ }^{-1}\right)$ \\
catechol & 110.11 & $9.34^{a}$ & $12.60^{a}$ & 0.972 & 0.028 & $0.53^{f}$ & 0.48 & -46.31 \\
pyrogallol & 126.11 & $9.12^{a}$ & $11.19^{a}$ & 0.954 & 0.046 & $0.47^{c, g}$ & 0.54 & -52.10 \\
4-methylcatechol & 124.14 & $9.59^{b}$ & $12.69^{c}$ & 0.983 & 0.017 & $0.42^{c}$ & 0.59 & -56.93 \\
3-methylcatechol & 124.14 & $9.59^{b}$ & $12.66^{c}$ & 0.984 & 0.016 & $0.42^{c}$ & 0.59 & -56.93 \\
3-methoxycatechol & 140.14 & $9.59^{c}$ & $12.69^{c}$ & 0.984 & 0.016 & $0.33^{c}$ & 0.68 & -65.61
\end{tabular}

${ }^{a}$ Experimental values. ${ }^{26,45}{ }^{b}$ Predicted using ChemAxon. ${ }^{27,28}{ }^{c}$ Calculated using linear free energy relationships. ${ }^{26,29,30}{ }^{d}$ At working pH 7.8. ${ }^{e}$ For the diprotic form $\mathrm{H}_{2} \mathrm{Q} .{ }^{f} \mathrm{At} \mathrm{pH}$ 7.0. ${ }^{g}$ Accounting for the equivalent $-\mathrm{OH}$ groups in carbons 1 and $3 .{ }^{h} \Delta E=E_{\mathrm{O}_{3} / \mathrm{O}_{3}}{ }^{--}-E_{\mathrm{H}_{2} \mathrm{Q}^{+*} / \mathrm{H}_{2} \mathrm{Q},}$ and $E_{\mathrm{O}_{3} / \mathrm{O}_{3}}{ }^{--}=1.01 \mathrm{~V}^{46}$ ${ }^{i} \Delta G^{\circ}=-n F \Delta E$. 
a large rate constant $k_{\mathrm{HO}+\text { catechol }}=1.1 \times 10^{10} \mathrm{M}^{-1} \mathrm{~s}^{-1}$. ${ }^{33}$ The rate constants for the aqueous reactions of pyrogallol, 3methoxycatechol, and 3- and 4-methylcatechols with $\mathrm{HO}^{\bullet}$ should be larger than that for catechol due to the presence of electron-donating groups. ${ }^{34}$ For example, the reaction rate constants for 3-methylcatechol and 4-methylcatechol with $\mathrm{HO}^{\bullet}$ (available in the gas phase) are 1.9 and 1.5 times larger than for catechol. ${ }^{35}$ Comparable oxidation conditions are supported by experiments under a fixed $100 \mu \mathrm{M}$ concentration for each substituted catechol at $\mathrm{pH} 7.8$ reacting with $2.7 \mathrm{ppmv} \mathrm{O}_{3}(\mathrm{~g})$, which constrain the produced $\left[\mathrm{HO}^{\bullet}\right]_{\text {interface }}=(1.1 \pm 0.3) \times$ $10^{13}$ radicals $\mathrm{cm}^{-3}$. Thus, the attack of $\mathrm{HO}^{\bullet}$ on the activated rings should also be expected to be $\geq 2 \times 10^{4}$ times larger than for the corresponding reaction with $\mathrm{O}_{3}\left(k_{\mathrm{O}_{3}+\text { catechol }}=5.2 \times 10^{5}\right.$ $\mathrm{M}^{-1} \mathrm{~s}^{-1}$ at $\left.\mathrm{pH} 7\right) .{ }^{36}$ Once $\mathrm{HO}^{\bullet}$ is produced, it can also directly abstract a hydrogen atom from $\mathrm{H}_{2} \mathrm{Q}$ to form $\mathrm{HQ}^{\bullet}$. Under typical atmospheric conditions, the competitive fate of the cyclohexadienyl radicals is fast $\mathrm{O}_{2}$ addition ${ }^{37}$ forming a peroxy radical that decomposes into a hydroxylated product releasing hydroperoxyl radical $\left(\mathrm{HO}_{2}{ }^{\circ}\right)$ by reaction $\mathrm{R} 12 .{ }^{38}$ Thus, reaction R12 represents the formation of pyrogallol $(\mathrm{m} / z$ 125) from catechol, 3-methyl-4-hydroxycatechol, 4-methylpyrogallol, and 4-methyl-5-hydroxycatechol (all $m / z$ 139) from 3- and 4methylcatechols, and 4-methoxypyrogallol and 3-methoxy-4hydroxycatechol (both with $\mathrm{m} / z$ 155) from anisole. It is particularly interesting to compare the relative ion counts for the first hydroxylated products $(\mathrm{m} / z$ 139) of both methylcatechols studied. The fact that $I_{139}$ for 4-methylcatechol is about 2 times larger than for 3-methylcatechol in experiments with $2.42 \mathrm{ppm} \mathrm{O}_{3}$ (Figure 2), and that their $\alpha_{\mathrm{H}_{2} \mathrm{Q}}, \alpha_{\mathrm{HQ}^{-}}$, and $E_{\mathrm{H}_{2} \mathrm{Q}^{\bullet+}} / E_{\mathrm{H}_{2} \mathrm{Q}}$ values (Table 1) are practically identical (Table 1) for both species, suggests that the efficiency for electron transfer must not be the cause for this discrepancy. Indeed, the presence of a vicinal $-\mathrm{CH}_{3}$ causes steric hindrance that could decrease the reactivity of 3-methylcatechol relative to 4methylcatechol for this electron transfer initiated process.

The quick production of $\mathrm{HQ}^{\bullet}$ and $\mathrm{HO}^{\bullet}$ is also reflected in Figure 3 showing the profiles of each species for increasing $\left[\mathrm{O}_{3}(\mathrm{~g})\right]$. For example, the top panel of Figure 3 shows how pyrogallol $(m / z 125)$ generates a large production of (1) 3- and 4-hydroxy-o-quinones $(\mathrm{m} / z$ 123) likely from self-reaction R7 and (2) tetrahydroxybenzenes $(m / z \quad 141)$ via the sequence represented by reaction $\mathrm{R} 13$. Reaction $\mathrm{R} 7$ can also be invoked for the considerable production of 4-methyl-o-quinone $(\mathrm{m} / z$ 121) from 4-methylcatechol in Figures 3. Interestingly, reaction R7 is not observed in the cases of 3-methylcatechol and 3methoxycatechol, showing the steric hindrance introduced by $-\mathrm{CH}_{3}$ and $-\mathrm{OCH}_{3}$ groups in position 3 (next to the bond with both $-\mathrm{OH}$ groups). In addition, reaction $\mathrm{R} 13$ also explains the large production of (1) 3-methyl-4,5-dihydroxycatechol and 4methyl-3,5-dihydroxycatechol (both $\mathrm{m} / z$ 155) from 3-methyl4-hydroxycatechol, 4-methylpyrogallol, and 4-methyl-5-hydroxycatechol and (2) 4-methoxy-5-hydroxypyrogallol and 3methoxy-4,5-dihydroxycatechol (both $m / z$ 171) from 4methoxypyrogallol and 3-methoxy-4-hydroxycatechol (both $m / z$ 155). Alternatively, another very likely mechanism for incorporation of $-\mathrm{OH}$ to the catechols (not displayed in Scheme 1) is the direct reaction with $\mathrm{O}_{3}$ at positions 3 and 6 that eliminates $\mathrm{O}_{2}\left({ }^{1} \Delta_{\mathrm{g}}\right)$. ${ }^{2,39,40}$

In general, the maximum $I_{m / z}$ values for the products from the first electrophilic addition of $\mathrm{HO}^{\bullet}$ to the substituted catechols via reaction $\mathrm{R} 13$ dominate the composition of products (see blue squares in Figure 3). However, pyrogallol is an exception due to its extraordinary ability to form 3- and 4hydroxy-o-quinones $(m / z 123)$. For increasing $\left[\mathrm{O}_{3}(\mathrm{~g})\right], I_{m / z}$ of the monohydroxylated products starts to decay, indicating further oxidation occurs. Interestingly, $I_{171}$ for 3-methoxycatechol (see teal stars in Figure 3) keeps growing instead of decaying for higher $\left[\mathrm{O}_{3}(\mathrm{~g})\right]$. This anomaly clearly indicates that 2-methoxymuconic acid originating from oxidative cleavage of the aromatic ring contributes further to the peak intensity than the isomeric second hydroxylation product of 3-methoxycatechol. Otherwise, less intense growing patterns are observed from reactions R13 and R14 for $I_{m / z}$ of the respective second and third hydroxylation products (see teal stars in Figure 3 ). Reaction R14 represents a third-generation product with a new $-\mathrm{OH}$ group added to ( 1$)$ tetrahydroxybenzenes $(\mathrm{m} / z$ 141) to form pentrahydroxybenzene $(\mathrm{m} / z \quad 157)$, (2) 3-methyl-4,5dihydroxycatechol and 4-methyl-3,5-dihydroxycatechol (both $\mathrm{m} / z$ 155) to form 3-methyl-4,5,6-trihydroxycatechol and 4methyl-3,5,6-trihydroxycatechol (both $m / z$ 171), and (3) 4methoxy-5-hydroxypyrigallol and 3-methoxy-4,5-dihydroxycatechol (both $m / z 171$ ) to form 4-methoxy-5,6-dihydroxypyrogallol $(\mathrm{m} / z$ 187). The conversion of pentahydroxybenzene into benzenehexol (reaction R15) represents a fourthgeneration aqueous product from catechol (Table S1, Supporting Information). ${ }^{2}$

The reactions for the production of all the quinones experimentally observed in Figures 1 and 2 can be explained to proceed analogously to self-reaction R7 and/or crossreaction $\mathrm{R} 8$. An alternate pathway for their production is the elimination of $\mathrm{H}_{2} \mathrm{O}_{2}$ after $\mathrm{O}_{3}$ attack to vacant positions 3 and 4 of the substituted catechols. ${ }^{2}$ These complex reactions likely proceed through a cyclic ozonide intermediate. ${ }^{36}$ The structures for the quinones named above for $m / z 121,123$, $137,139,153,155,169$, and 171 are provided in Table S2 (Supporting Information) together with the corresponding precursors. Figure 3 shows the profiles of these quinones are slightly less intense than the corresponding $\mathrm{H}_{2} \mathrm{Q}$ species $2 \mathrm{amu}$ heavier but generally resemble each other's behavior with increasing $\left[\mathrm{O}_{3}(\mathrm{~g})\right]$.

Oxidative Cleavage of Substituted Catechols. While the substituted catechols react at the air-water interface, generating a distribution of products dominated by the functionalized aromatic rings described in Scheme 1, fragmentation of the bond between $\mathrm{C}_{1}$ and $\mathrm{C}_{2}$ by electrophilic $\mathrm{O}_{3}$ generates polyfunctional carboxylic acids. The small ion count for the representative fragmentation products with $\mathrm{m} / \mathrm{z}$ 89 and 99 included in Figure 3 is expected because these secondary oxidation products cannot accumulate during the short $\tau_{\mathrm{c}}$ in the setup. ${ }^{16}$ The detailed analysis explaining the mechanism of reaction for catechol ${ }^{2}$ should also be applicable to its substituted counterparts. Catechol, pyrogallol, both methylcatechols, and 3-methoxycatechol undergo a series of oxidative fragmentations summarized in Scheme 2 to yield muconic acid $(m / z 141)$, 2-hydroxymuconic acid $(m / z 157)$, 2and 3-methylmuconic acids $(\mathrm{m} / z$ 155), and 2-methoxymuconic acid $(m / z 171)$, respectively.

The produced substituted muconic acids result from an ozonide that is sequentially converted into a Criegee intermediate and a hydroperoxide that also releases $\mathrm{H}_{2} \mathrm{O}_{2}{ }^{2}$. Scheme 2 also shows that further fragmentation by $\mathrm{O}_{3}$ and in situ generated $\mathrm{H}_{2} \mathrm{O}_{2}$ produces glyoxylic $(\mathrm{m} / z 73)$, crotonic $(\mathrm{m} /$ $z 85)$, pyruvic $(\mathrm{m} / z 87)$, 3-oxopropanoic $(\mathrm{m} / z \mathrm{87})$, oxalic $(\mathrm{m} / z$ $89)$, maleinaldehydic $(\mathrm{m} / z$ 99), 4-hydroxy-2-butenoic $(\mathrm{m} / z$ 
Scheme 2. Products and Observed $m / z$ Values from Substituted Catechol Oxidation by $\mathrm{O}_{3}$ and $\mathrm{H}_{2} \mathrm{O}_{2}$ Following the Mechanisms from Ref $2^{a}$

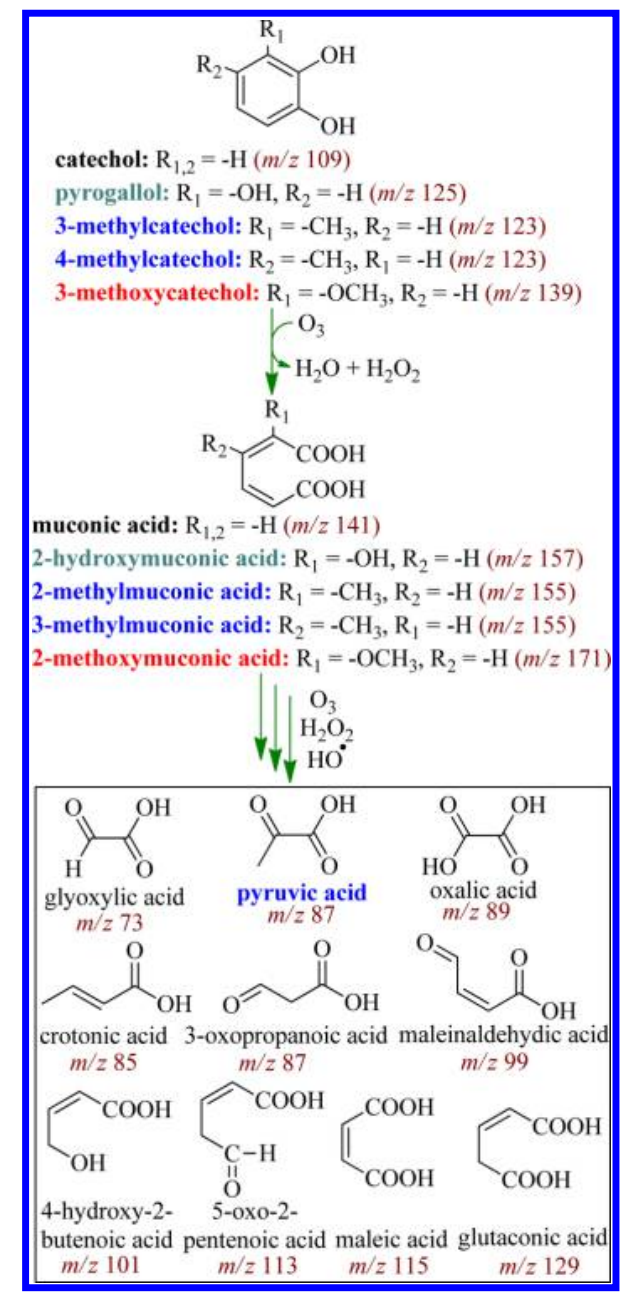

${ }^{a}$ Names in bold colored fonts match the precursors and products.

101), 5-oxo-3-pentenoic $(m / z 113)$, maleic $(m / z 115)$, and glutaconic $(m / z 129)$ acids. ${ }^{2}$ While the majority of the compounds (e.g., glyoxylic and oxalic acids) could originate from all the catechols, the color coding in Scheme 2 clearly indicates that pyruvic acid only arises from the oxidation of the methylcatechols. Thus, together with the pathways from isoprene photooxidation, ${ }^{22,41}$ the oxidative channel for the oxidation of methylated aromatics such as toluene, producing cresols (reactions R1 and R2), is responsible for the production of this important tropospheric compound.

The common oxidative fate of the low molecular weight carboxylic acids is to continue getting oxidized en route to form $\mathrm{CO}, \mathrm{CO}_{2}$, oxalic acid, and formic acid. Interestingly, glyoxylic acid was the most abundant product during the oxidation of catechol at the air-water interface, lasting $\tau_{\mathrm{c}} \approx 1 \mu \mathrm{s}$. $^{2}$ Glyoxylic acid can be oxidized to form oxalic acid $(\mathrm{m} / \mathrm{z} 89)$, ${ }^{2}$ but photooxidation in water yields $\mathrm{CO}, \mathrm{CO}_{2}$, formic acid, glyoxal, and a small amount of tartaric acid. ${ }^{23}$ Both pyruvic and glyoxylic acid also yield these common products by BaeyerVilliger (BV) oxidation in the presence of in situ generated $\mathrm{H}_{2} \mathrm{O}_{2}{ }^{2}$. In addition, a comparison of the reactivity of both methylcatechols shows that the $-\mathrm{CH}_{3}$ group in position 3 creates a more electron rich vicinal carbon-carbon bond with
$-\mathrm{OH}$ groups and enhances fragmentation by electrophilic $\mathrm{O}_{3}$. The previous fact can be visualized in Figure 2 as well as by the brown times signs for $m / z 99$ in the center panel of Figure 3. Consequently, a slight increase in the number of low molecular weight carboxylic acids is observed for 3-methylcatechol relative to 4-methylcatechol. Finally, it is possible to consider the attack of $\mathrm{HO}^{\bullet}$ on the substituted catechols followed by the addition of $\mathrm{O}_{2}$ to form an endoperoxide that will add a second $\mathrm{O}_{2}$. The peroxide formed can decompose, contributing quinones and mainly low molecular weight carbonyls and carboxylic acids. For example, the production of glyoxal, glyoxylic acid, oxalic acid, methylglyoxal, and pyruvic acid from both methylcatechols can proceed through this channel.

Implications. This laboratory study contributes to characterizing the evolution of combustion and biomass burning emissions, an important subject to understand how the surface of carbonaceous materials is affected during interfacial oxidations that can potentially alter the morphology of particles that play a role in the direct radiative effect. ${ }^{42}$ The most important process governing the initial oxidation of aromatic species in the atmosphere is controlled by the presence of $\mathrm{HO}^{\circ}$. The results from ultrafast experiments analyzed by mass spectrometry reveal the identity of low-volatility reaction products. Quinone (Table S2, Supporting Information) and polyphenol reactive intermediates coexist at the air-water interface, where low molecular weight carboxylic acids found in brown clouds are produced. The quick oxidation of all substituted catechols proceeds by competing functionalization and fragmentation reactions. Although for acidic hygroscopic particles containing sulfate a lower amount of hydroxyl radical should be generated in situ by the electron transfer mechanism presented, the reactions of phenols with this radical will proceed as reported here regardless of the source of $\mathrm{HO}^{\bullet}$. Thus, the studied phenols, available on the surface of tropospheric particles, should react with impinging $\mathrm{HO}^{\bullet}$ produced in the gas phase through the same pathways presented.

The proposed pathways agree with observations previously made for catechol at the air-water and air-solid interfaces under variable relative humidity, ${ }^{2,3}$ which generate more hydrophilic products that partition into the aqueous phase. In addition, photochemical oxidation should also contribute to the degradation of aromatics in the aqueous phase. ${ }^{43}$ However, the substituted catechols display an enhancement in their reactivity due to the ring-activating functional groups. Similarly, the functionalized rings with more $-\mathrm{OH}$ groups are also highly activated toward fragmentation and should be relevant intermediates in the degradation of aromatics emitted during combustion and biomass burning. In addition, this information can also be applied to support the similar chemical processing of particulate matter with a diameter of $<1 \mu \mathrm{m}\left(\mathrm{PM}_{1}\right)$ from the greater London area in winter 2012. ${ }^{44}$ This $\mathrm{PM}_{1}$ contains nonvolatile organics associated with refractory black carbon that could originate from either combustion or biomass burning emissions. Finally, this work also explains typical degradation pathways for aromatic pollutants derived from benzene, toluene, and anisole in water media and at the air-water interface.

\section{ASSOCIATED CONTENT}

\section{S Supporting Information}

The Supporting Information is available free of charge on the ACS Publications website at DOI: 10.1021/acs.est.7b00232. 
Additional environmental justification and tables giving the parent species and produced hydroxy aromatics expected from Scheme 1 and names, structures, observed $\mathrm{m} / \mathrm{z}$ values, and precursors of the produced quinones (PDF)

\section{AUTHOR INFORMATION}

\section{Corresponding Author}

*Phone: 859-323-2892; fax: 859-323-9985; e-mail: marcelo. guzman@uky.edu.

\section{ORCID}

Marcelo I. Guzman: 0000-0002-6730-7766

Notes

The authors declare no competing financial interest.

\section{ACKNOWLEDGMENTS}

We thank the National Science Foundation for funding under NSF CAREER Award CHE-1255290.

\section{REFERENCES}

(1) Boucher, O.; Randall, D.; Artaxo, P.; Bretherton, C.; Feingold, G.; Forster, P.; Kerminen, V.-M.; Kondo, Y.; Liao, H.; Lohmann, U.; Rasch, P.; Satheesh, S. K.; Sherwood, S.; Stevens, B.; X.Y. Zhang, X. Y. Clouds and Aerosols. In Climate Change 2013: The Physical Science Basis. Contribution of Working Group I to the Fifth Assessment Report of the Intergovernmental Panel on Climate Change; Stocker, T. F., Qin, D., Plattner, G.-K., Tignor, M., Allen, S. K., Boschung, J., Nauels, A., Xia, Y., Bex, V., Midgley, P. M., Eds.; Cambridge University Press: Cambridge, U.K., New York, 2013.

(2) Pillar, E. A.; Camm, R. C.; Guzman, M. I. Catechol oxidation by ozone and hydroxyl radicals at the air-water interface. Environ. Sci. Technol. 2014, 48 (24), 14352-14360.

(3) Pillar, E. A.; Zhou, R.; Guzman, M. I. Heterogeneous oxidation of catechol. I. Phys. Chem. A 2015, 119 (41), 10349-10359.

(4) O’Neill, E. M.; Kawam, A. Z.; Van Ry, D. A.; Hinrichs, R. Z. Ozonolysis of surface-adsorbed methoxyphenols: kinetics of aromatic ring cleavage vs. alkene side-chain oxidation. Atmos. Chem. Phvs. 2014, 14 (1), 47-60.

(5) Barnum, T. J.; Medeiros, N.; Hinrichs, R. Z. Condensed-phase versus gas-phase ozonolysis of catechol: A combined experimental and theoretical study. Atmos. Environ. 2012, 55, 98-106.

(6) Woodill, L. A.; O’Neill, E. M.; Hinrichs, R. Z. Impacts of Surface Adsorbed Catechol on Tropospheric Aerosol Surrogates: Heterogeneous Ozonolysis and Its Effects on Water Uptake. L.Phvs. Chem. A 2013, 117 (27), 5620-5631.

(7) Henze, D. K.; Seinfeld, J. H.; Ng, N. L.; Kroll, J. H.; Fu, T. M.; Jacob, D. J.; Heald, C. L. Global modeling of secondary organic aerosol formation from aromatic hydrocarbons: high- vs. low-yield pathways. Atmos. Chem. Phvs. 2008, 8 (9), 2405-2420.

(8) Atkinson, R.; Arey, J. Atmospheric degradation of volatile organic compounds. Chem. Rev. 2003, 103 (12), 4605-4638.

(9) Calvert, J. G.; Atkinson, R.; Becker, K. H.; Kamens, R. M.; Seinfeld, J. H.; Wallington, T. J.; Yarwood, G. The Mechanisms of Atmospheric Oxidation of the Aromatic Hydrocarbons; Oxford University Press: New York, 2002; p 566.

(10) Atkinson, R.; Aschmann, S. M. Rate constants for the gas-phase reactions of the $\mathrm{OH}$ radical with the cresols and dimethylphenols at $296 \pm 2 \mathrm{~K}$. Int. I. Chem. Kinet. 1990, 22 (1), 59-67.

(11) Veres, P.; Roberts, J. M.; Burling, I. R.; Warneke, C.; de Gouw, J.; Yokelson, R. J. Measurements of Gas-phase Inorganic and Organic Acids from Biomass Fires by Negative-ion Proton-transfer Chemicalionization Mass Spectrometry. I. Geophvs. Res. 2010, 115, D23302.

(12) Desyaterik, Y.; Sun, Y.; Shen, X.; Lee, T.; Wang, X.; Wang, T.; Collett, J. L. Speciation of "brown" carbon in cloud water impacted by agricultural biomass burning in eastern China. $\underline{\text { L Geophys. Res.-Atmos. }}$ 2013, 118 (13), 7389-7399.
(13) Latif, M. T.; Brimblecombe, P. Surfactants in Atmospheric Aerosols. Environ. Sci. Technol. 2004, 38 (24), 6501-6506.

(14) Dharaiya, N.; Bahadur, P. Phenol induced growth in Triton X100 micelles: Effect of $\mathrm{pH}$ and phenols' hydrophobicity. Colloids Surf. A 2012, 410 (0), 81-90.

(15) Guzman, M. I.; Athalye, R. R.; Rodriguez, J. M. Concentration Effects and Ion Properties Controlling the Fractionation of Halides during Aerosol Formation. I. Phvs. Chem. A 2012, 116 (22), 54285435.

(16) Pillar, E. A.; Guzman, M. I.; Rodriguez, J. M. Conversion of Iodide to Hypoiodous Acid and Iodine in Aqueous Microdroplets Exposed to Ozone. Environ. Sci. Technol. 2013, 47 (19), 10971-10979.

(17) Kawamura, K.; Tachibana, E.; Okuzawa, K.; Aggarwal, S. G.; Kanaya, Y.; Wang, Z. F. High abundances of water-soluble dicarboxylic acids, ketocarboxylic acids and $\alpha$-dicarbonyls in the mountaintop aerosols over the North China Plain during wheat burning season. Atmos. Chem. Phvs. 2013, 13 (16), 8285-8302.

(18) Andreae, M. O.; Merlet, P. Emission of trace gases and aerosols from biomass burning. Global Biogeoch. Cv. 2001, 15 (4), 955-966.

(19) Alves, C. A.; Gonçalves, C.; Pio, C. A.; Mirante, F.; Caseiro, A.; Tarelho, L.; Freitas, M. C.; Viegas, D. X. Smoke emissions from biomass burning in a Mediterranean shrubland. Atmos. Environ. 2010, 44 (25), 3024-3033.

(20) Parmar, R. S.; Satsangi, G. S.; Kumari, M.; Lakhani, A.; Srivastava, S. S.; Prakash, S. Study of size distribution of atmospheric aerosol at Agra. Atmos. Environ. 2001, 35 (4), 693-702.

(21) Paulot, F.; Jacob, D. J. Hidden cost of U.S. agricultural exports: Particulate matter from ammonia emissions. Environ. Sci. Technol. 2014, 48 (2), 903-908.

(22) Carlton, A. G.; Turpin, B. J.; Lim, H.-J.; Altieri, K. E.; Seitzinger, S. Link between isoprene and secondary organic aerosol (SOA): Pyruvic acid oxidation yields low volatility organic acids in clouds. Geophvs. Res. Lett. 2006, 33 (6), 06822.

(23) Eugene, A. J.; Xia, S.-S.; Guzman, M. I. Aqueous photochemistry of glyoxylic acid. I. Phus. Chem. A 2016, 120 (21), 3817-3826.

(24) Sander, S. P.; Abbatt, J.; Barker, J. R.; Burkholder, J. B.; Friedl, R. R.; Golden, D. M.; Huie, R. E.; Kolb, C. E.; Kurylo, M. J.; Moortgat, G. K.; Orkin, V. L.; Wine, P. H. Chemical Kinetics and Photochemical Data for Use in Atmospheric Studies: Evaluation Number 17; Jet Propulsion Laboratory, California Institute of Technology: Pasadena, CA, 2011; http://jpldataeval.jpl.nasa.gov.

(25) Charbouillot, T.; Brigante, M.; Mailhot, G.; Maddigapu, P. R.; Minero, C.; Vione, D. Performance and selectivity of the terephthalic acid probe for $\mathrm{OH}$ as a function of temperature, $\mathrm{pH}$ and composition of atmospherically relevant aqueous media. I. Photochem. Photobiol., A 2011, 222 (1), 70-76.

(26) Perrin, D. D.; Dempsey, B.; Serjeant, E. P. pKa Prediction for Organic Acids and Bases; Chapman and Hall: London, 1981.

(27) Wishart, D. S.; Jewison, T.; Guo, A. C.; Wilson, M.; Knox, C.; Liu, Y.; Djoumbou, Y.; Mandal, R.; Aziat, F.; Dong, E.; Bouatra, S.; Sinelnikov, I.; Arndt, D.; Xia, J.; Liu, P.; Yallou, F.; Bjorndahl, T.; Perez-Pineiro, R.; Eisner, R.; Allen, F.; Neveu, V.; Greiner, R.; Scalbert, A. HMDB 3.0-The Human Metabolome Database in 2013. Nucleic Acids Res. 2013, 41, D801-D807.

(28) Wishart, D. S.; Knox, C.; Guo, A. C.; Shrivastava, S.; Hassanali, M.; Stothard, P.; Chang, Z.; Woolsey, J. DrugBank: a comprehensive resource for in silico drug discovery and exploration. Nucleic Acids Res. 2006, 34, D668-D672.

(29) Zhu, X.-Q.; Wang, C.-H.; Liang, H. Scales of oxidation potentials, $\mathrm{pKa}$, and $\mathrm{BDE}$ of various hydroquinones and catechols in DMSO. L. Org. Chem. 2010, 75 (21), 7240-7257.

(30) Steenken, S.; Neta, P. Electron transfer rates and equilibriums between substituted phenoxide ions and phenoxyl radicals. I. Phvs. Chem. 1979, 83 (9), 1134-1137.

(31) Steenken, S.; Neta, P. Properties of Phenoxyl Radicals. In The Chemistry of Phenols; Rappoport, Z., Ed.; John Wiley \& Sons: New York, 2003; p 1000. 
(32) Elliot, A. J.; McCracken, D. R. Effect of Temperature on O•Reactions and Equilibria: A Pulse Radiolysis Study. Radiat. Phvs. Chem. 1989, 33 (1), 69-74.

(33) Buxton, G. V.; Greenstock, C. L.; Helman, W. P.; Ross, A. B. Critical Review of Rate Constants for Reactions of Hydrated Electrons, Hydrogen Atoms and Hydroxyl Radicals $\left({ }^{\circ} \mathrm{OH} /{ }^{\circ} \mathrm{O}^{-}\right)$in Aqueous Solution. I. Phvs. Chem. Ref. Data 1988, 17 (2), 513-886.

(34) Schwarzenbach, R. P.; Gschwend, P. M.; Imboden, D. M. Environmental Organic Chemistry; Wiley: New York, 2005.

(35) Olariu, R. I.; Barnes, I.; Becker, K. H.; Klotz, B. Rate coefficients for the gas-phase reaction of $\mathrm{OH}$ radicals with selected dihydroxybenzenes and benzoquinones. Int. I. Chem. Kinet. 2000, 32 (11), 696-702.

(36) Mvula, E.; von Sonntag, C. Ozonolysis of Phenols in Aqueous Solution. Org. Biomol. Chem. 2003, 1 (10), 1749-1756.

(37) Mvula, E.; Schuchmann, M. N.; von Sonntag, C. Reactions of Phenol-OH-Adduct Radicals. Phenoxyl Radical Formation by Water Elimination vs. Oxidation by Dioxygen. J. Chem. Soc. Perk. T. 2 2001, No. 3, 264-268.

(38) Adams, G. E.; Michael, B. D. Pulse Radiolysis of Benzoquinone and Hydroquinone. Semiquinone Formation by Water Elimination from Trihydroxy-cyclohexadienyl Radicals. Trans. Faradav Soc. 1967, 63 (0), 1171-1180.

(39) Von Sonntag, C.; Von Gunten, U. Chemistry of Ozone in Water and Wastewater Treatment: From Basic Principles to Applications; IWA Publishing: London, 2012; p 302.

(40) Iwaki, R.; Kamiya, I. Chemiluminescent Reaction between Polyphenols and Ozone in Acetic Acid. Bull. Chem. Soc. Ipn. 1969, 42 (4), 855-863.

(41) Guenther, A.; Jiang, X.; Heald, C. L.; Sakulyanontvittaya, T.; Duhl, T.; Emmons, L. K.; Wang, X. The Model of Emissions of Gases and Aerosols from Nature version 2.1 (MEGAN2. 1): an extended and updated framework for modeling biogenic emissions. Geosci. Model Dev. 2012, 5, 1471-1492.

(42) Saleh, R.; Adams, P. J.; Donahue, N. M.; Robinson, A. L. The interplay between assumed morphology and the direct radiative effect of light-absorbing organic aerosol. Geophys. Res. Lett. 2016, 43 (16), $8735-8743$.

(43) Vione, D.; Maurino, V.; Minero, C.; Pelizzetti, E.; Harrison, M. A. J.; Olariu, R.-I.; Arsene, C. Photochemical reactions in the tropospheric aqueous phase and on particulate matter. Chem. Soc. Rev. 2006, 35 (5), 441-453.

(44) Xu, L.; Williams, L. R.; Young, D. E.; Allan, J. D.; Coe, H.; Massoli, P.; Fortner, E.; Chhabra, P.; Herndon, S.; Brooks, W. A.; Jayne, J. T.; Worsnop, D. R.; Aiken, A. C.; Liu, S.; Gorkowski, K.; Dubey, M. K.; Fleming, Z. L.; Visser, S.; Prevot, A. S. H.; Ng, N. L. Wintertime aerosol chemical composition, volatility, and spatial variability in the greater London area. Atmos. Chem. Phys. 2016, 16 (2), 1139-1160.

(45) CRC Handbook of Chemistry and Physics, 93rd ed.; CRC Press/ Taylor and Francis: Boca Raton, FL, 2013; p 2664.

(46) Flyunt, R.; Leitzke, A.; Mark, G.; Mvula, E.; Reisz, E.; Schick, R.; von Sonntag, C. Determination of ${ }^{\bullet} \mathrm{OH}, \mathrm{O}_{2}{ }^{\bullet}$, and Hydroperoxide Yields in Ozone Reactions in Aqueous Solution. I. Phys. Chem. B 2003, 107 (30), 7242-7253. 